\section{EMBRYRIDDLE}

Aeronautical University

SCHOLARLY COMMONS
Journal of Aviation/Aerospace

Education \& Research

Volume 19

Number 2 JAAER Winter 2010

Article 1

Winter 2010

\title{
A Historical Perspective for Incorporating the Airframe and Powerplant Certificate as a Relevant Engineering Technology Skill
}

J. M. Thom

S. I. Dubikovsky

T. C. Hagovsky

R. M. Hendricks

Follow this and additional works at: https://commons.erau.edu/jaaer

\section{Scholarly Commons Citation}

Thom, J. M., Dubikovsky, S. I., Hagovsky, T. C., \& Hendricks, R. M. (2010). A Historical Perspective for Incorporating the Airframe and Powerplant Certificate as a Relevant Engineering Technology Skill. Journal of Aviation/Aerospace Education \& Research, 19(2). https://doi.org/10.15394/jaaer.2010.1369

This Article is brought to you for free and open access by the Journals at Scholarly Commons. It has been accepted for inclusion in Journal of Aviation/Aerospace Education \& Research by an authorized administrator of Scholarly Commons. For more information, please contact commons@erau.edu. 


\title{
A HISTORICAL PERSPECTIVE FOR INCORPORATING THE AIRFRAME AND POWERPLANT CERTIFICATE AS A RELEVANT ENGINEERING TECHNOLOGY SKILL
}

\author{
J.M. Thom, S.I. Dubikovsky, T.C. Hagovsky, D.L. Stanley and R.M. Hendricks
}

At first, the concept of an engineering technology program containing an Airframe and Powerplant certificate (A\&P) program might seem to be odd. At many colleges and universities the A\&P program is considered to be a vocational certificate program, while the engineering program is considered to be more of a professional degree program. The engineering faculty credentials and mandated classroom requirements for engineering have traditionally been diametrically opposed with the A\&P certification. But on second look the combination of these two disciplines may not be as odd as it first seems. In fact, the A\&P curriculums in four-year colleges today are not that different from where the profession of engineering was in 1900. By understanding the roots of engineering education, and the changes in engineering education over the last century, it becomes easy to see how the A\&P certificate holds relevance in engineering education.

\section{Engineering: Vocational education or profession}

Engineering education has gone through several iterations over the past one hundred years. At the beginning of the twentieth century, the profession of engineering was very much a hands-on occupation. In fact at the beginning of the twentieth century many colleges and universities did not consider engineering a true profession worthy of university study (Mann, C.R., 1918). Up through the 1950s and 1960s students studying engineering learned many hands-on skills. Mechanical engineers learned to operate industrial machine tools, do metal casting, perform welding, and to operate the advanced machinery of the day. Whether it be firing a steam locomotive or turning parts on a lathe, engineers learned how to actually do things. In aeronautical engineering in 1946 students learned how to do such things as drill holes and drive rivets, form sheet metal, weld, and operate aircraft engines (Purdue University, 1945). Figures 1,2 , and 3 shown in the pages that follow show engineering students in 1945 involved in hands-on applications that were considered to be important experiential knowledge for design engineers. 


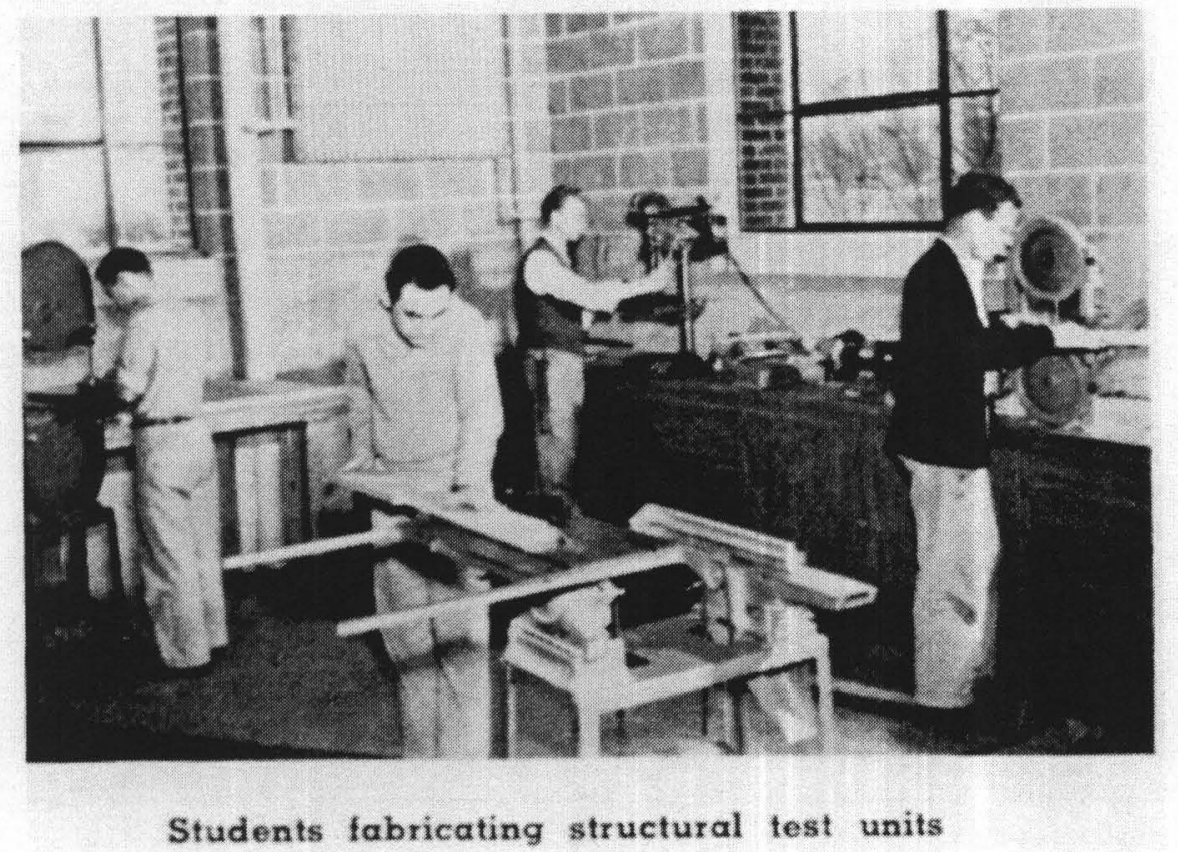

Figure 1. Aeronautical Engineering Students circa 1945

Throughout the twentieth century engineering education changed. The various engineering studies done on the state of engineering development, ranging from the Mann Report to the Gritner Report, detailed the evolution of engineering from a highly vocational program to a theoretically based science program (Thom, J.M. and Thom, M.A., 2006). Throughout the twentieth century engineering struggled to be accepted at colleges and universities as a legitimate profession. Like many of the current A\&P programs, engineering had to constantly work to convince the academic elite that engineering deserved consideration as a true "profession." Only in the later half of the twentieth century were engineering programs given, begrudgingly in some cases, the recognition of being a "profession" (Thom, M.A., 2004). 


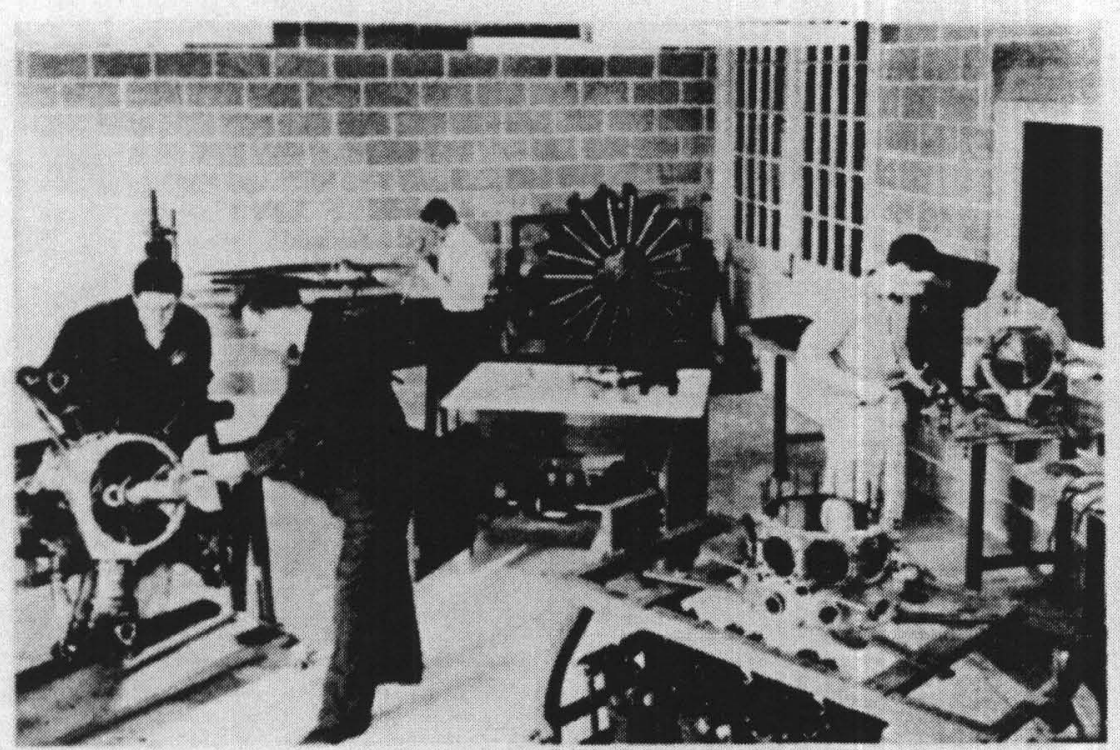

\section{A corner of the disassembly laboratory, showing some of the} facilities available for work on aircratt engines

Figure 2. Aeronautical Engineering Students circa 1945

Following the publication of the Gritner report in the 1950s engineering was divided into two parts: applications and science. By the late 1950s there was pressure at major universities to remove the vocational aspects of the engineering curriculums. By the early $1960 \mathrm{~s}$ the portions of the engineering programs that worked with the hands-on applications were given to engineering institutes. Those portions of engineering that studied the theory were given to four-year engineering programs. The academic credentials of the faculty at engineering institutes were to be different than that of the four year engineering programs. Faculty at the institutes were expected to have master's degrees and the curriculum was designed to produce engineers with the hands on capabilities that industry had needed. Faculty at the four year engineering colleges were expected to have PhDs, and this was where the science, theory, and research was to be done (Grinter, L.E., 1955).

Unfortunately, this strategy of a "bifurcated" engineering program did not work. Because the graduates of the four-year programs tended to enter college many of the same hands-on skills as the graduates from the engineering institutes, employers opted for graduates from the four-year programs under the philosophy that the four year engineering school graduate had both inherent hands-on knowledge and engineering science. Employers in industry felt that the graduates from the engineering institutes, while technically very good, did not possess the science skills of the four-year engineering graduate (Thom, M.A., 2004). Faced with declining interest from industry, the engineering institutes gradually faded away. Some morphed into fouryear engineering programs and became prestigious engineering schools of which many people may have heard: Massachusetts Institute of Technology, California Institute of Technology, etc.

The decline of the technology-based engineering programs was facilitated by economic pressures within universities. Applications laboratories were expensive to maintain and operate. Faced with the choice of allocating resources, engineering programs found it preferable to eliminate the expensive applications labs and rely on engineering lectures. Additionally, without the need for students to attend time consuming applications labs, the number of credit hours in engineering programs could be 
reduced. In 1957 a mechanical engineer at Purdue University would have accumulated approximately 173 credit hours, much of which was hands-on applications training. By the year 1999 a similarly degreed engineer would only have 128 credit hours, and often no hands-on experience of any kind. In the ever tightening budgets of colleges and universities, the elimination of the applications courses allowed for dramatic reductions in credit hours (Thom, M.A., 2004).

Another aspect of the problem is today's economy and global nature of it. In some respects, the U.S. is not ready for it. U.S. engineers now have to compete with their colleagues from around the world. This creates new set of problems, not present in the 1960s. Level of engineering education in countries such China and India is very bigh. Those countries are playing "catch-up game", and they are very successful in their efforts. Thus, there is no longer room in engineering for graduates who do not have the knowledge or skills to incorporate the needed practical knowledge into their designs and decisions. The need to encourage the study of engineering in the U.S. is becoming more important as globalization and information sharing helps other countries compete with the U.S. and many traditional engineering activities are outsourced. Hands-on projects help keep students interested in technology and helps to retain them in the engineering studies (Costlow, T. 2005).

\section{A successful profession, but at a cost}

At the end of the twentieth century engineering had become a true "profession" in the United States. Unfortunately the industries that engineering was serving were expressing a growing discontent with the product of the engineering schools. The "old school" engineers of the 1950 s were all literally dying off, and the graduates of the modern programs lacked the applications skills to fill the traditional role of engineer (Thom, M.A., 2004). The young engineers no longer entered college with hands-on skills as did their 1950s predecessors, and those colleges no longer taught the hands on skills. The old engineers working in industrial settings could not understand why the fresh-out graduates "didn't know anything." Industry processes were still based on an assumption of a graduating engineer who had some hands-on exposure to complement the engineering science. By 1999 this was no longer a valid paradigm. This dissatisfaction with engineering graduates came to a head between 1995 and 2000 . The organization responsible for the accreditation of engineering and engineering technology programs ABET, Inc. (formerly the Accreditation Board for Engineering and Technology) responded to the strong concerns from industry and created new standards for engineering and engineering technology program. The new standards introduced at the beginning of the twentieth century allowed engineering programs greater flexibility and allowed a return to more applications based programs. What this new ABET criteria for engineering technology essentially did was re-affirm the value of the engineering institutes advocated in the Gritner Report. At that point, with the blessing of ABET accreditation, industries needing technically competent graduates could look to more application based programs for graduates to fill "engineering" positions. These standards adopted in 2000 and 2001 became the criteria for use today.

\section{Aviation education challenges}

Those trying to maintain A\&P programs at universities and colleges in the latter half of the twentieth century have faced a host of challenges. Declining enrollments in traditional A\&P programs have been one issue, leaving schools to scramble to capture a market share of a declining pool of applicants. Failure by the Federal government and the aviation industry to advance the certification of the A\&P as a professional level career has also caused difficulties. Fitting what has traditionally been considered by many college level administrators to be a "vocational" program into a collegiate setting has been another challenge.

The expense of starting up or maintaining an aircraft maintenance based program lead to the demise of some programs. Interestingly enough these were all the same challenges faced by engineering at the beginning of the twentieth century (Mann, C.R., 1918) and (Grinter, L.E., 1955). Engineering chose paths to solve these problems which again bear remarkable similarity to the types of solutions chosen by many collegiate A\&P schools at the end of the twentieth century.

In an attempt to adapt and survive there have been several strategies employed by collegiate A\&P programs over the past thirty years. One strategy has been to allow the A\&P program to become a basic vocational education program. Another strategy has to choose to abandon the A\&P program and become a "maintenance management" or "aviation management" program. And yet another strategy has been to attempt to become an engineering or engineering technology program. Each of these strategies has come with risk to the programs which chose them.

For programs choosing, or have chosen for them, to become primarily vocational programs, the result has been a disassociation with university programs providing students with the kind of broad educational background 
necessary to create a well rounded professional in aviation and aerospace. States and universities which have pushed the A\&P programs "downward" to a level on par with a vocational program equivalent to automotive maintenance or plumber, have contributed to shortage of aviation professionals with specific technical knowledge who are needed to nun and operate aerospace manufacturing operations, aerospace design, airline management, and aviation management. No disrespect is intended here, nor implied, for anyone studying a vocational trade such as plumbing, automotive repair, building construction, etc. However it is arguable that the A\&P technician should be placed on an equivalent level based on the degree of training, certification, responsibility, and liability the A\&P assumes. While there continues to be a need for A\&P programs that have a narrow maintenance focus, the trend has been by colleges and universities to stereotype all A\&P programs in the 18-24 month vocational education program.

To allow A\&P education to be pigeon holed into an exclusively vocational education role is to deny the fact that the aerospace manufacturing and operations of the twenty first century needs leaders who have specific technical knowledge of the "nuts and bolts" of how aircraft are designed, built, operated, and repaired. Failure to acknowledge technical programs as being professional has shown to be problematic in other professions already. To abandon the A\&P completely in pursuit of a generic "management" degree is problematic as well. A program that produces "managers" runs the risk of creating graduates who lack the technical knowledge to effectively make decisions in a technically complex industry. It can deprive the graduates of the detailed mechanical knowledge to understand why operations and maintenance is conducted the way it is. It deprives the "managers" of the kind of knowledge they need to collaborate with organized labor unions in the ways quality management requires in a global economy. And, it deprives managers of the vocabulary and knowledge to communicate effectively with the technicians doing the actual work. This divide has been shown to be especially pronounced among young female managers who already have fears of appearing ignorant in a male dominated business (Thom, J.M., \& Pickering, M. 2002)and (Thom, J.M., Pickering, M. \& Thompson, R.E. 2002). When the language and the technical knowledge is removed from the manager's education, the inability of the managers to successfully communicate and understand technical problems becomes catastrophic.

The model developed and fostered by colleges and universities for the past fifty years where the college graduate has science and theory knowledge and no specific experiential skills has proven to be a failure repeatedly in the United States (Thom, M.A., 2004). The complete abandonment by ABET of this system for creating engineers in the year 2000 acknowledges the failure to recognize the hands-on skills as an essential ingredient in education. The fact that there are those in the petrochemical industry who have given up on hiring chemical engineers to manage and operate chemical and refining facilities, but instead has chosen to partner with technical schools for these jobs is one indicator (Depew, 2004). The study done by researchers at the U.S. Air Force Academy in the mid 1990s regarding failures in the space program which were linked to engineers who did not understand the designs of the past is another example (Scott, W.B., 1999, 1999a, 1999b).

A program in the United States Navy (USN) using what is known as Limited Duty Officers (LDO) is another example. The USN has a program for promoting enlisted personnel to the officer ranks. These Limited Duty Officers come from the enlisted ranks and can rise to the level of full Commander in the USN. The purpose of the LDO is to provide the USN with managers and planners who have risen through the technical ranks and know the technical specifics of how to maintain ships, how to manage personnel, how to repair aircraft, how to operate a shipyard. (Mick, 2006). This program is an outright recognition that the college graduates who become commissioned officers (college graduates) lack the experience to manage and maintain the ships, aircraft, and personnel of the USN. A college graduate coming in to the USN as an Ensign does not have the experience or technical background to successfully plan and execute operations involving highly technical knowledge such as aircraft maintenance. So the USN has created a system by which they recognized the value of the enlisted personnel who do have the technical knowledge, and provide a professional executive career path for those technical people to become leaders

Some collegiate A\&P schools have chosen to attempt to maintain their technical education by becoming fully accredited engineering schools. The engineering curriculum in these schools replaces the A\&P curriculum. The risk in this movement is that it is difficult to become a top rated engineering school. New faculty must be hired, and a completely new set of industrial partners must be courted. At the time that the school is evolving from a top rated A\&P program to a new engineering program, there is a loss of industrial support from the traditional industrial partners and a lack new support from industrial partners in the engineering worlds. The risk is that the program 
transactions from being a top rated $A \& P$ program to a thirdrate engineering program. Additionally, if an A\&P program originally resided in a college or university which already had engineering programs there is the problem competing with another department in their own college or university for funding and survival.

Another problem with becoming an engineering school is that without the A\&P as a core value, there is little defense against administrators who wish to reduce the hands-on exposure of the students to the aerospace vehicles, the construction techniques, the operational requirements, and the highly technical details of aircraft maintenance and operation. In scenarios that resemble what happened to the engineering community in the latter half of the twentieth century, academic administrators decide to reduce credit hours in the program, reduce hands-on laboratory time, eliminate "expensive" equipment and replace it with computer code, and emphasize courses that are more "professional." It has happened at even the most successful schools in engineering and it happens in those A\&P programs transitioning to engineering programs. It also happens in A\&P programs that transition to management programs. The temptation to teach theory of management, theory of engineering, business in a global environment, advanced mathematics, and courses improving the "soft skills," begin to replace rather than enhance the teaching of applied technical concepts (Thom, M.A., 2004).

Engineering education has for many years had a heavy emphasis on teaching engineers what has been called "soft skills" in the hope that engineers can learn how to acquire the necessary technical, interpersonal, environmental, and situational knowledge to make proper engineering decisions. What the proponents of the "soft skills" education fail to realize is that great interpersonal skills and sociological training cannot totally replace the intimate knowledge of the processes and techniques require to build, maintain and operate systems.

\section{The $A \& P$ as an engineering program}

Even the basic A\&P of the future will have to know more sophisticated technical information and at a higher level. The A\&P of the future will have to assume leadership rolls in business and industry.

Aerospace by its very nature is a highly technical environment and its leaders must understand the technical details in order to effectively make management and engineering decisions. In the new century, for successful companies, the day of the professional manager who has no specific technical knowledge is over. Lack of basic understanding of manufacturing processes, for example, could cause a whole conceptual design to be side-tracked and delayed. Relying too much on computers without such needed basic knowledge could make any project a disaster. Without "gut feel," which comes only with practical experience, many mistakes are possible and very likely to be made. As the saying in computer science goes, "garbage in = garbage out." Computer code and management models are only as accurate as the technical information we can put into them.

One of most important areas of engineering is materials science. It is not enough for aviation maintenance personnel to know how to repair riveted joints, for example. It is many times more important to understand how the repair affects the whole structure of the aircraft. The industry does not need just mechanics. It needs persons with technical knowledge who can apply technical knowledge system wide. The trend in North America has been toward a reduction in manufacturing related jobs, but at the same time U.S. manufacturing companies claim they have serious problems finding qualified candidates for the highly technical world of modern manufacturing (Bouckley, S., 2006). What indicates is that people trained in the traditional roles in the past do not have the cross-functional knowledge for the $21^{\text {st }}$ Century industries. Engineers and managers need more technical knowledge, and the technicians need more engineering and management.

The FAA currently specifies the basic knowledge required to become an A\&P. However, the schools must find ways to link that A\&P to other required skills. There is still a place for the A\&P at many places to be taught vocationally. There is nothing wrong with that. However, the A\&P knowledge is a valuable body of technical information that when coupled to other professional knowledge becomes tremendously powerful. It has been the experience of these authors that when the A\&P has been linked to a traditional engineering program that the results have been dramatic. The graduates of these dual degree programs have been in high demand by aerospace manufacturers and the careers of these graduates have presented far better opportunities than with either degree by itself. This package of engineering and maintenance knowledge also creates a graduate that is very much like the traditional engineer of the early twentieth century. As mentioned previously, in 1957 a graduating mechanical engineer from Purdue University would have 173 credits hours on their transcript. Many of these hours were laboratory hours where these engineers learned to weld, work on engines, and even operate a high pressure steam powerplant. Aeronautical engineers at the time learned to 
rivet, bend sheet metal, plumb hydraulic systems and overhaul aircraft powerplants (Purdue University, 1945);

(Thom, M.A., 2004).

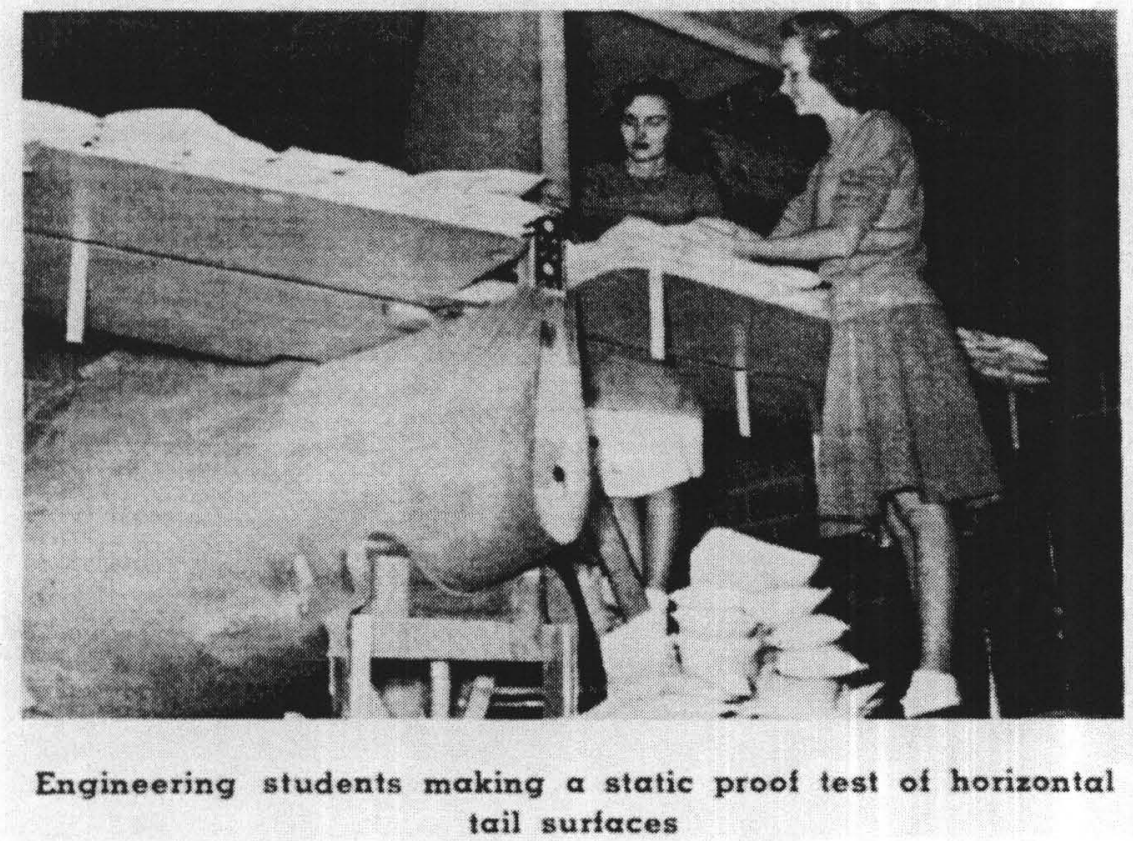

Figure 3. Aeronautical Engineering Students circa 1945

In the late 1990 s the Department of Aviation Technology at Purdue University was partnered with multiple traditional engineering departments at Purdue to be able to offer students a dual degree. The student could receive an A\&P and B.S. in Aviation Technology, and a B.S. in engineering. These students graduated with 181 credit hours and they had received extensive hands on experience to accompany their engineering theory. So, by the end of the twentieth century, it took two B.S. degrees and an A\&P certificate to provide industry with graduates with the applications knowledge equivalent to the engineer of 1957.

Given the new TAC ABET criteria, it is possible to pursue the $A \& P$ and engineering technology degree in one package in a more reasonable amount of credit hours. The recognition of the industry that graduates for engineering jobs had to have more hands-on experience has driven this change. Using the $A \& P$ as the centerpiece of an engineering technology program can serve several goals. It can provide a plan of study at collegiate based A\&P programs which is of value to industry. Graduates with the A\&P plus engineering technology can find higher level positions in aerospace than with the A\&P alone, and the graduates can find positions at a wider variety of companies. In the current climate, organizations value and engineers or managers with the A\&P knowledge base even though that graduate may never be asked to perform direct hands-on maintenance. The kinds of companies interested in these higher level A\&Ps are more likely to be organizations that can command the attention of college or university administrators, and are more likely to be corporations with grants, internships, and other programs of importance to college and university administrators. By the nature of the jobs these graduates can get, the overall professionalism and respect for the A\&P in general is enhanced. The A\&P by its definition provides an outcome based direction for teaching and a capstone event, both of which are prized under not only ABET, but all of higher education's outcomes-based accreditation system. The ability of a graduate to come from an ABET accredited curriculum opens doors that otherwise would be closed should the graduate be looking for employment with a major aerospace manufacturer. The A\&P provides a stabilizing influence on curriculums, faculty, and programs, and provides a common goal for faculty. The A\&P places a perspective on safety, responsibility, and risk management which is not available in an ordinary engineering program. 
Contrary to what many might believe the A\&P certificate is respected among many in the engineering community. While there are probably few engineers who would want A\&Ps to design airfoils, perform stress analyses, or do laminar flow computations, all of the engineers nationally that these authors have talked to in the process of moving Purdue's A\&P program toward an engineering technology program, have been encouraging that the A\&P is a desirable body of knowledge for the engineering technologist. These engineers all believe the body of knowledge from the A\&P provides graduates with the ability to perform the tasks related to engineering, but which traditional engineers no longer know how to do. The A\&P based engineering technologists can do things such as, develop manufacturing processes, design fabrication tooling, create test plans, manage technicians, document processes, ensure regulatory compliance, interface with parts suppliers and fabricators, manage specifications, perform CAD operations, integrate CAM operations, troubleshoot technical problems, provide assistance with historical design context, etc.

The authors found that some of the engineering schools in the U.S. had in the past attempted to partner with vocational schools in order to bring the hands-on elements into the engineering curriculums. The engineering programs reported varying degrees of success with those efforts, with the primary limitation being that most vocational school students did not possess the basic mathematics ability needed to succeed in the pre-ABET 2000 world of engineering science. But, today's A\&P education environments at four-year colleges enjoy two advantages that did not exist for these traditional engineering programs attempting to marry with vocational programs. First, the ABET requirements in the post 2000 standards allow for a much greater flexibility in what can be included in an engineering program. Second, the A\&P programs which exist in four-year colleges and universities often already have students with the mathematics abilities to perform at an acceptable level in basic calculus and physics. So, the movement of an A\&P program toward engineering technology is also a movement recognized as a positive direction even among some engineering educators.

There are of course challenges to a move to engineering technology from a program which has historically been A\&P based. ABET requires that the faculty for an engineering program have "appropriate" credentials. What this means is that there must probably have to be some engineers on the faculty. While at the onset it looks impossible to have an A\&P program with engineers teaching in it, it is not impossible. There are hands-on engineers out there who can fill the role of engineer and hands-on educator. There are even A\&Ps with engineering technology credentials and PhDs. They are hard to find but they are there. Should the collegiate based A\&P and engineering technology programs become more common place these faculty should begin to become more commonplace over the course of a couple of generations. In the short term, careful curriculum planning and careful faculty hiring can help keep this from being a problem. The ABET criteria also does not define all faculty must be engineers for an engineering technology program. Where non-engineering faculty are better suited to teaching material related to specific outcomes, faculty with those credentials should be hired. For example, engineers typically have very little background in statistical analysis, while many faculty with master's degrees teaching in aviation programs in some form of technical education have some education in statistical analysis. And, a robust statistics background might be a priority of an A\&P based engineering technology program and proves to be a valuable mathematics type skill in the Six Sigma Quality world of aerospace engineering most engineers do not have.

Upgrading course content to the rigors of an engineering technology program can also be a challenge. The first priority is to not make the mistake of trying to become a traditional engineering science program where every class is filled with blackboards full of calculus proofs. The A\&P students might have to learn some calculus to use a calculus formula to solve a problem to get a number for a materials course or a hydraulics course, but there is very little need for them to sit through hours and hours of formula creations. Just as students in an A\&P program are not asked to design an open end wrench; just to use it properly, they should not be expected to invent (prove) formulas but rather to simply use the mathematical formula (the tool) to fix a problem. In an A\&P based engineering technology program, the students may be given more math, algebra, trigonometry, and calculus formulas to use, but this is a much different than the old school of engineering science. Faculty may have to stretch a little to meet the new goals, but in reality the generation of college educated A\&Ps who are coming along should be able to perform at a level beyond that those who are considered to be "old timers" can do today. The example could be made that just as new generations of A\&P instructors are able to teach avionics and composite structures that the old "dope and fabric" and radial engine instructors might not be able to teach, new generations of A\&P instructors who can teach the math behind turbine 
engine performance and calculated strength of materials can take the A\&P to the next level of engineering technology. They should be able to do this and still maintain the handson experience needed for aircraft repair and maintenance. After having examined both engineering education and technology education for several years at the collegiate level, it has become evident to these authors that there are many analytical and interpretive activities done by the A\&P technologist, that are beyond the current engineering science student to comprehend and integrate. So in its own ways the technology content is just as challenging as the engineering program content. The advanced technology of aircraft maintenance, construction, and design that is within the purview of the A\&P engineering technologist is challenging enough to be an engineering technology in its own right. It is therefore not unreasonable to believe that the A\&P experience can be a substantial portion of an engineering technology curriculum. Exactly how the A\&P can be incorporated into an engineering technology curriculum is complex, and the authors need more space than this article allows to detail how that can be done. The authors intend to discuss the development of an A\&P based engineering technology curriculum in later articles. The intent here, however, is to show that the relevant skills contained in the A\&P programs are long valued concepts that have a place in engineering technology.t

James M. Thom is an associate professor at Purdue University. He had overseen a certificate course in logistics, has taught design life cycle cost analysis courses, and has been the principal investigator for three studies on engineering education. Professor Thom holds an A\&P certificate and teaches aviation maintenance and engineering technology. Prior to coming to Purdue he worked for eleven years as a field engineer for a major aerospace corporation and participated in design engineering and integrated support logistics activities.

Sergey Dubikovsky is an assistant professor at Purdue University in the Aviation Technology department. He teaches advanced aircraft materials and processes, and advanced manufacturing and design courses. His research focus is in immersive learning, team building, problem and project-based learning, international engineering education, globalization, Lean Six Sigma, threaded and specialized fasteners. He worked previously in industry as a design, product and project engineer. He has undergraduate and graduate degrees in Mechanical Engineering from South Ural State University (formerly Chelyabinsk Polytechnic Institute) in Russia.

Thomas Hagovsky is an associate professor at Purdue University in the Aviation Technology program. He teaches nondestructive testing for aircraft, advanced aircraft systems, and technician responsibilities. His research is focused in the electronic delivery of information (DE) area. His B.A. degree is from University of Louisiana-Lafayette in General Studies, a M.A. degree in Education from Ohio University, and a Ph.D. in Higher Education Administration from Purdue University. He has been a certificated FAA Airframe and Powerplant (A\&P) Mechanic for 27 years with extensive experience in the helicopter industry.

David Stanley is an associate professor at Purdue University in the Aviation Technology program He teaches basic aircraft science, powerplant propulsion systems and powerplant systems. His research is focused in the area of bio-fuels and alternative fuels for aviation applications. He has a B.S. degree in Aviation Technology, a B.A. degree in Math and English Education, and a M.S. degree in Industrial Technology, all from Purdue University.

Renee Hendricks is an assistant professor at Purdue University in the Aviation Technology department. She teaches aircraft electrical systems, avionics systems, and aviation security courses. Her research focus is in avionics, access control devices, biometrics, project-based learning, and radio frequency I.D. tagging. Renee worked previously in industry as a security system engineer. She has a B.S. in Electrical Engineering Technology and an M.S. in Industrial Technology. 


\section{References}

Bouckley, S. (2006). Filling Workforce Skill Gaps. Manufacturing Engineering, 137- 2, p. 18-19.

Costlow, T. (2005). Projects Pose Grand Challenge. Design News. 60-18.

D. R. Depew. Dean College of Technology, Purdue University. (Personal Communication, December 2004).

Grinter, L.E . (1955). Report of the committee on evaluation of engineering education (a.k.a. The Grinter report). Journal of Engineering Education, pp 25-60. Accessed September 21, 2004 from www.asee.org.

Mann, C.R. (1918). A study of engineering education, Bulletin number 11. NY: The Carnegie Foundation for the Advancement of Teaching.

P.J. Mick, Faculty, Purdue University, and American Council on Education accreditation team member. (Personal Communication, December, 2006)

Purdue University, Department of Aeronautical Engineering (1945). Aviation At Purdue.

Scott, W.B. (1999). Aerospace Management 'People' issues are cracks in aero industry foundation. Aviation Week \& Space Technology. Retrieved July 7, 1999, from http://www.aviationweek.com/ aviation/aw63-66.htm

Scott, W.B. (1999a). Aerospace Management New management incentives are key to change. Aviation Week \& Space Technology. Retrieved July 7, 1999, from http://www.aviationweek.com/ aviation/aw63-66a.htm

Scott, W.B. (1999b). Aerospace Management 'Hire-and-fire' paradigm is obsolete. Aviation Week \& Space Technology. Retrieved July 7, 1999, from http://www.aviationweek.com/aviation/aw63-66b.htm

Thom, J.M. and Thom, M.A. (2006)_Back to the Future: A survey of Engineering and Technology Education over the Last Century. Aviation Technical Education Council Journal. 28-1., 24-30.

Thom, M.A. (2004). Perceptions of Practitioners and Engineering Educators and Students Regarding Requisite Skills for Effective Design of Complex Systems. Unpublished Masters Thesis. Purdue University, West Lafayette, Indiana.

Thom, J.M., \& Pickering, M. (2002). A New Look at Motivators for Women to Enter Aviation Maintenance, Aviation Technical Education Council Journal, 23-2,4-8.

Thom, J. M., Pickering, M, and Thompson R. E. (2002). Understanding the barriers to recruiting women in engineering and technology programs-study results. Paper presented at the Frontiers in Education Conference in Boston, MA 